\title{
Origens do Brasil meridional: dimensões da imigração polonesa no Paraná, $1871-1914$
}

\section{Origins of Southern Brazil: the importance of Polish immigration in Paraná, $1871-1914$}

Márcio de Oliveira

Os estudos sobre o tema da imigração no Brasil oscilam entre a perspectiva da imigração espontânea e a da imigração subvencionada, também chamada de "oficial". No caso da primeira, os fatores de expulsão são mais relevantes que os fatores de atração. ${ }^{1}$ A fome de terra e de trabalho, a explosão demográfica, as imagens do El Dorado, o desenvolvimento das estradas de ferro e das linhas marítimas e a correspondência enviada por imigrantes estão entre os mais impor-

Marcio de Oliveira é professor de sociologia da UFPR (marciodeoliveira@ufpr.br).

Artigo recebido em 27 de novembro de 2008 e aprovado para publicação em 8 de janeiro de 2009.

Nota do autor: Esta pesquisa contou com o apoio da Capes para pós-doutorado realizado na França e conta com o apoio do CNPq.

Estudos Históricos, Rio de Janeiro, vol. 22, n 43, janeiro-junho de 2009, p. 218-237. 
tantes fatores de expulsão. Mas fala-se ainda no fim das proibições ("liberdade de partir") e na emancipação dos camponeses, decorrentes do fim da servidão e da invenção do passaporte (Torpey, 2000). No caso da imigração subvencionada, a dita liberdade de entrar é emoldurada por ações públicas (por vezes pontuais) favorecendo o acesso à terra e/ou ao trabalho. Foi esse "modelo portas abertas" que atraiu indivíduos e famílias, colonos e trabalhadores para o continente americano, em especial para os EUA, destino preferido dos imigrantes europeus (Green, 1994). Um e outro modelo, é claro, inserem-se no contexto maior do processo de industrialização e de avanço do capitalismo nas terras centrais da Europa (Blanc-Chaleard, 2001).

No caso do Brasil, o modelo de atração aparentemente se impôs para todo o período que vai dos anos 1820 à década de 1930, mesmo que, a partir dos anos 1920, a política de imigração tenha se tornado mais restritiva (Ramos, 1994). Em princípio, esse modelo serviria para explicar tanto o caso dos imigrantes alemães e poloneses ${ }^{2}$ quanto o dos imigrantes italianos (em sua grande maioria) e japoneses. Contudo, quando se examina com mais profundidade as políticas de atração organizadas pelo Império e pela República, e/ou pelas províncias e estados durante o período em tela, percebe-se que diferenças existem. A transição para o mercado livre de trabalho, que se produziu no decorrer da segunda metade do século XIX, modificou o sentido da imigração. No lugar de imigrantes-colonos, o estado de São Paulo, por exemplo, passou a privilegiar a vinda de trabalhadores agrícolas. A edificação em 1887, pela Sociedade Promotora de Imigração, da Hospedaria do Imigrante na cidade de São Paulo confirma essa tendência (Alvim, 2000).

A imigração japonesa para o Brasil é mais um exemplo que confirma a política do estado de São Paulo de atrair trabalhadores agrícolas. Foi uma imigração "tutelada”, ou seja, dirigida conjuntamente por São Paulo e pelo Estado japonês, por intermédio da empresa Kaigai Kogyo Kabuschiki Kaisha (Handa, 1987; Sakurai, 2000). Por outro lado, os imigrantes alemães, poloneses ou ucranianos, e mesmo italianos, que, em sua grande maioria, se instalaram nos estados da região Sul desde os anos 1820 até as primeiras décadas do século XX, são considerados verdadeiros colonizadores. Contudo, suas diversas trajetórias e objetivos, ou ainda a forma como foram incorporados à paisagem social local, demonstram que o mesmo modelo de atração encobre realidades muito distintas. Excetuando-se os alemães, de longe o grupo étnico mais estudado (Willems, 1946; Roche, 1959; Seyferth, 1974, 1981, 2000), o caso dos ucranianos mereceu poucos estudos, enquanto o dos poloneses, que se instalaram nos estados do Paraná e do Rio Grande do Sul a partir dos anos 1870, permanece até hoje objeto de pesquisa local (Wachowicz, 1977, 1981, 1999; Kersten, 1983; Andreazza, 1996; Guérios, 2006; Gritti, 2004; Wencznowicz, 2009). 


\section{A imigração no Paraná como questão}

Entre os casos particulares, a imigração para o estado do Paraná é um exemplo emblemático. Isso ocorre porque desde sua origem ela se encontra a meio caminho entre os dois modelos descritos, ou seja, apresenta-se como uma resultante de ações públicas locais e federais e dos próprios imigrantes. Além disso, tendo-se iniciado antes que o Paraná se emancipasse do estado de São Paulo, a imigração (e as imagens positivas que lhe foram sendo associadas) tornou-se uma das questões-chave na trajetória de ocupação e colonização do território, e na própria definição da identidade cultural do estado (Oliveira, 2007).

Embora as ações públicas locais realizadas para atrair imigrantes tenham tido, como veremos, efeito bastante limitado, o número de estrangeiros que chegou ao Paraná revela-se bastante importante. Para o que nos interessa aqui, nada menos do que 40 mil poloneses ${ }^{3}$ lá chegaram entre 1870 e 1914, fazendo do Paraná o estado que mais recebeu imigrantes desse grupo. Além disso, as primeiras levas de poloneses se instalaram nos arredores da capital do estado, Curitiba, constituindo pequenas comunidades relativamente homogêneas, mas entrando também em contato com outros grupos de imigrantes e, é claro, tecendo relações comerciais e sociais com os moradores da capital. Sua chegada aconteceu ainda no momento mesmo em que a emigração polonesa para outros países da Europa e para o continente americano foi a mais importante, $o$ que nos permite verificar e talvez redefinir o papel das políticas de atração no âmbito da imigração.

Finalmente, como a imigração polonesa para o Brasil coincidiu com a época em que movimentos nacionalistas atuantes nos territórios ocupados se organizavam para reconquistar a independência do Estado polonês, a questão da emigração tornou-se um assunto de primeira grandeza. Tendo em vista o grande número de poloneses vivendo de forma aparentemente isolada e em comunidades consideradas homogêneas, em especial no Brasil, mas também na Argentina, e, obviamente, os problemas que isso significava para aqueles movimentos tanto em termos de potencial de recrutamento quanto em termos da redefinição da identidade polonesa, uma grande expedição científica foi organizada no intuito de verificar in loco as condições de vida dos "patrícios" nos dois países. Conforme veremos mais tarde, muitos dos imigrantes instalados no Paraná se viram assim às voltas com interesses nacionalistas e mesmo neocolonizadores, tendo seu papel migrado, em termos simbólicos e políticos, de colono-imigrante para emigrante-colonizador cujo objetivo final seria criar uma colônia da nação polonesa em terras brasileiras. Para compreender a trajetória desse grupo étnico no Brasil, e em especial no Paraná, decidimos voltar ao período em questão, ou seja, entre os anos 1870 e 1920 . Acompanhando a trajetória da imigração polonesa para o 
Brasil (particularmente para o Paraná), focamos nosso interesse nas relações entre os fatores de expulsão e os fatores de atração (pull-push factors) e na forma como a imigração foi finalmente percebida nos dois lados do Atlântico.

\section{A questão da imigração no Paraná entre 1854 e 1870}

Comparando o Paraná com seus estados vizinhos do Sul, tratava-se do menos populoso. Em 1872, tinha apenas $127 \mathrm{mil} \mathrm{habitantes,} \mathrm{contra} 159 \mathrm{mil} \mathrm{em}$ Santa Catarina e 446 mil no Rio Grande do Sul (Recenseamento do Brasil, 1872). ${ }^{4}$ Até sua emancipação, em 1854, o estado conhecera diversas experiências de colonização dirigidas por estrangeiros, tais como a "Colônia de Superagui", fundada e dirigida por Ch-Henri Perret, e a "Colônia Teresa", fundada e dirigida pelo médico francês Jean-Maurice Faivre. A partir de 1854, em praticamente todos os relatórios dos presidentes da província enviados à Assembleia Provincial, ${ }^{5}$ fez-se menção lisonjeira a esse tipo de colonização. $O$ primeiro presidente da província, Zacarias Góes, enumerou algumas de suas vantagens: o cultivo de alimentos, considerado uma alternativa econômica à tradicional pesca, a catequização dos indígenas e a introdução de população "laboriosa” (Relatório, 1854 (1): 53-57). Não obstante, afirmou ainda Zacarias, as colônias não poderiam prosperar sem o devido apoio do governo imperial, que só envidava esforços para os empreendimentos situados nas regiões fronteiriças do Império.

No Relatório de 1860, o presidente da província afirmava que o imigrante europeu "não nos demanda sem que lhe sejam dispostos previamente os meios de recebê-lo" (Relatório, 1860: 61). Sem esconder certo pesar, afirmava ainda não ter podido acolher imigrantes por não ter terras devolutas demarcadas a lhes oferecer. No Relatório de 1864 (1), o presidente afirmava que a imigração colonizadora não avançava, "não obstante a amenidade e temperamento do clima" (Relatório, 1864 (1): 29).

Inúmeras dificuldades entravaram a imigração até 1870. Por um lado, a questão era uma prerrogativa do Império, que se interessou principalmente pelas regiões fronteiriças. Por outro lado, a província não dispunha de terras devolutas para vender aos imigrantes, e a Lei de Terras (1850) - que tornou a "terra" uma mercadoria - dificultou a compra de lotes pelos imigrantes, mesmo dos posseiros que residiam no interior da província (Relatório, 1865: 57). Em resumo, portanto, não se pode dizer que houve uma política de imigração voltada para os interesses provinciais nesse período. É interessante, assim, observar as circunstâncias que fizeram com que a província passasse a agir de maneira mais direta em relação à imigração. 


\section{A imigração polonesa para o Paraná, primeiro ato: 1870-1889}

Em 1870 chegou a Curitiba, também de forma espontânea, o primeiro grupo de imigrantes poloneses. Nesse momento, a Polônia não existia como país independente. Seus territórios, desde fins do século XVIII, estavam divididos entre os impérios Austro-Húngaro, Russo e Prussiano. Essa partilha durou até as vésperas da Primeira Guerra Mundial, englobando assim o período mais importante da emigração polonesa para as Américas (EUA, Argentina e Brasil). As causas da emigração são bem conhecidas. Entre as mais importantes, temos a "fome" de terra, a miséria, as magras colheitas e o sonho de se tornar "proprietário rural", particularmente decisivo para aqueles que emigravam para a América do Sul.

Hempel (1973: 85) afirma que a chegada dos primeiros poloneses ao Brasil foi obra da Sociedade Colonizadora Pereira, Alves \& Bendaszewski, igualmente responsável pela emigração de um incontável número de poloneses e alemães para os EUA. Esse primeiro grupo havia partido da região da Silésia (sob ocupação prussiana). A Prússia não colocava obstáculos à emigração e concedia passaporte aos que desejavam partir. Contudo, apesar dos pedidos nesse sentido, o governo imperial brasileiro se recusou a pagar os custos da viagem (400 francos por cabeça) alegando tratar-se de "imigração espontânea". Desembarcados no Brasil, e munidos de passaporte emitido pela Prússia, os poloneses foram imediatamente enviados às "zonas de colonização alemã", as colônias de Blumenau, Itajaí e Brusque, todas em Santa Catarina.

Foi Wós Saporski, ${ }^{6}$ imigrante polonês já radicado no Paraná, que tentou convencer esse grupo de poloneses a deixar Santa Catarina, onde mantinham relações tensas com os imigrantes alemães, e ir para Curitiba. Mas esse primeiro projeto fracassou, e apenas em 1871 um grupo de 78 poloneses ( 32 famílias), residentes em Santa Catarina havia já dois anos, decidiu partir para Curitiba, convencido pelo mesmo Saporski que, então, se havia tornado professor em uma escola da cidade. Nessa migração interna, o grupo enfrentou a resistência das autoridades catarinenses, que não desejavam ver "seus" imigrantes partirem, e do governo Imperial, para o qual pouco interessava a migração entre províncias. Mas, por outro lado, contou com o apoio do governo do Paraná, que custeou a viagem até Curitiba, ${ }^{7}$ enquanto a municipalidade, valendo-se de suas terras livres, se comprometia a vender lotes rurais em seus arredores. Os lotes, cuja área total era de 500 hectares, foram demarcados em novembro de 1871 . Nasceu então a primeira colônia polonesa do Paraná, a colônia do Pilarzinho, hoje um bairro de Curitiba.

No mês de setembro de 1873, 258 outros poloneses (64 famílias), originários da colônia de D. Francisca (SC), se instalaram espontaneamente em Curitiba e pediram à Câmara Municipal a demarcação de lotes de terra. Os lotes fo- 
ram demarcados em uma área contígua à recém-criada colônia do Pilarzinho, perfazendo um total de 720 hectares. Em homenagem a Frederico Abranches, presidente da província entre 1873 e 1874, a nova colônia recebeu o nome de Abranches, e também é hoje um bairro de Curitiba. Esses dois exemplos demonstram a maneira como a colonização ocorreu, as dificuldades encontradas e exatamente que tipo de apoio os primeiros colonos obtiveram das autoridades locais. ${ }^{8}$

No Relatório de 1873 (2), afirma-se que até aquela data, 13 de junho, 809 imigrantes teriam chegado espontaneamente à província, 454 dos quais se encontravam provisoriamente instalados na cidade de Curitiba, em uma localidade denominada "Barigui 370", talvez a primeira "hospedaria de imigrantes" de que se tem notícia na província. No Relatório de 1875 (1), verifica-se que viviam na província 2.633 imigrantes, dos quais 2 mil nos arredores da capital. Foi nesse momento que se deu a atuação, julgada crucial para a continuação da imigração para Curitiba, em especial a imigração polonesa, do presidente Lamenha Lins.

Tendo presidido a província entre maio de 1875 e janeiro de 1878, Lins se dirigiu pela primeira vez à Assembleia Legislativa em fevereiro de 1876. Demonstrou ser conhecedor do tema da imigração, diferenciando inicialmente a "espontânea" da "oficial". Em seguida, localizando a história da imigração no interior da recente história do Império, afirmou que o sucesso das primeiras colônias de poloneses era fruto de sua proximidade com a capital, enumerando as condições que guiariam sua ação, cujo sentido geral seria apoiar e direcionar aquela imigração espontânea que já afluía à província: "dizer a verdade ao imigrante", "facilitar-lhe o transporte", "dividir bons lotes de terra nas vizinhanças dos centros populosos", "evitar que ao chegar o imigrante sofra vexames", "estabelecer bem o colono, com todos os favores prometidos e, depois, libertá-lo de qualquer tutela" (Relatório, 1876 (1): 78-79). Em termos práticos, Lins custeou a viagem dos novos imigrantes dos portos de Paranaguá (PR) e São Francisco (SC) até Curitiba, estimulou a criação de novas colônias nos arredores da capital e cuidou de sua infraestrutura e acesso. Em termos demográficos, ao final de sua presidência, durante a qual foram criadas as colônias Santa Cândida, Orleans, Santo Inácio, D. Pedro, D. Augusto, Rivière, Muricy e Lamenha (a mais importante em número de colonos), aproximadamente 6 mil imigrantes poloneses viviam nos arredores de Curitiba (Relatório, 1877: 81-85). ${ }^{9}$

Por tudo isso, Lins foi de fato o primeiro presidente de província a estabelecer, em termos econômicos e políticos, uma relação positiva entre colonização do território, desenvolvimento rural e imigração. Mas não seria exagero dizer que sua ação ideológica e prática rompeu, ainda que brevemente, com a dicotomia entre "imigração espontânea" e "imigração oficial". Isso torna sua atuação objeto raro de estudo, nos permitindo explorar as diversas dimensões dos processos sociais imigratórios. 
O Relatório de 1880 (p. 45-61) apresenta um quadro bastante completo da imigração e da situação das colônias. ${ }^{10}$ Ao total, 39 núcleos coloniais e 21 colônias foram recenseados, com dados inclusive sobre o estado e a ocupação de lotes e moradias. Igualmente, todas as despesas públicas realizadas nesses núcleos ou colônias foram aí detalhadas. A título de exemplo, nota-se que a província havia realizado despesas em alimentação e transporte de colonos, melhoria de estradas, roçadas, demarcações, construído moradias em alguns núcleos coloniais, mas não necessariamente em todos eles, ficando à margem dessas benfeitorias justamente aqueles descritos como "prósperos" - casos de Thomaz Coelho e Inspetor Carvalho - ou "laboriosos e morigerados", Lamenha e Muricy. Isso é bastante curioso quando se sabe que as demandas dos colonos, sobretudo aquelas ligadas à construção de escolas ou melhorias na vias de ligação, são mencionadas no referido relatório.

Embora Lamenha Lins tenha colocado em novo patamar a ação oficial em relação à imigração, tomando-se o período imperial como um todo, deve-se concluir que esta cresceu de forma espontânea, sendo que o apoio da província continuou a ser feito de forma pontual e limitada, dependendo na maior parte das vezes de ações dos próprios imigrantes. Os números finais da imigração polonesa para o Paraná entre 1870 e 1889 parecem confirmar essa hipótese: apenas 7.030 poloneses se instalam na província nesse período. ${ }^{11}$ Não obstante, ao final desse primeiro período, uma consequência havia sido produzida: a ideia que os imigrantes eram necessários para o povoamento e a riqueza da província. E essa imagem não mais seria esquecida (Oliveira, 2007).

\section{A imigração polonesa durante a Primeira República}

Os anos que se seguiram à instauração da República coincidiram com o grande fluxo de imigrantes poloneses para o Brasil. Entre 1890 e 1914, 96.116 poloneses aportaram na cidade do Rio de Janeiro, para em seguida se dirigir aos estados. Durante aqueles anos, o Paraná teria recebido 35.116 poloneses, enquanto o Rio Grande do Sul aparece em segundo lugar, com 32 mil novos imigrantes. No primeiro grande fluxo, 1890-1894, também conhecido como o período da "febre brasileira", ${ }^{12}$ numerosas colônias foram criadas, tanto nos arredores de Curitiba quanto em outras regiões do estado. Entre elas, as mais importantes são: São Mateus ( 1.225 colonos), d'Eufrosina (1.475 colonos) e Rio Claro (3.425 colonos). No período do segundo grande fluxo, 1900-1904, foram criadas ainda as colônias de Cruz Machado (5.000 colonos), Apucarana (1.000 colonos) e a colônia mista de Nova Galícia (650 poloneses e 500 ucranianos). ${ }^{13}$ 
As razões do crescimento do fluxo migratório, não apenas de poloneses, não devem ser procuradas nas ações organizadas pela jovem República brasileira. Isso porque, durante os "anos 1890, multiplicam-se as intervenções visando a retirar do governo federal a prerrogativa de agir e de legislar em matéria de imigração" (Ramos, 2004: 78). Rigorosamente falando, assistiu-se, nestes primeiros anos, a um vai-e-vem entre a União e os estados em relação às competências legais em matéria de imigração. Pelo Decreto 528 (de 28 de junho de 1890), o governo republicano se dispôs a reembolsar de forma "total ou parcial" o valor das passagens de navio da Europa ao Brasil. ${ }^{14}$ Por sua vez, a Constituição de 1891 transferiu aos estados o controle das terras públicas, ditas "terras devolutas", ${ }^{15} \mathrm{e}$ estabeleceu que a entrada de "estrangeiros válidos, aptos ao trabalho e não perseguidos pela justiça de seus países de origem" era livre. ${ }^{16} \mathrm{Em}$ 1894, a imigração e a colonização tornaram-se competências exclusivas dos estados, e o papel da União ficou limitado ao controle dos portos e fronteiras e à primeira triagem dos imigrantes. Ainda assim, em alguns casos, foi a União quem encaminhou os imigrantes aos estados. Já em 1896, a União decidiu interromper suas ações de subvenção. É difícil avaliar, portanto, o impacto dessas medidas nos estados. Segundo Petrone (1978: 98-99), apenas São Paulo teria se beneficiado dessas medidas. E isso duraria até 1906, quando a União finalmente modificou sua política de imigração.

O Paraná, inicialmente, teria sido especialmente agraciado quando da transferência de terras públicas da União para os estados. Contudo, localmente, as ações empreendidas com vistas à atração de imigrantes permaneceram, durante a última década do século XIX, praticamente as mesmas do período imperial, a saber, restritas à demarcação e venda de lotes, acrescidas da prática de propagandear, nos "centros europeus", as vantagens que os futuros imigrantes encontrariam no estado. Essas práticas, cuja eficácia foi pequena, foram lastreadas pela relação positiva, que definitivamente se consolidou no plano local, entre imigração, ocupação do território e desenvolvimento do estado, o que tornaria a entrada de imigrantes um fato político corriqueiro e a imigração um tema sempre abordado. Isso pode ser comprovado em quase todas as "Mensagens ao Congresso Legislativo do Paraná”, enviadas anualmente, entre 1892 e 1920, pelos chefes do Executivo local aos deputados estaduais. ${ }^{17}$

$\mathrm{Na}$ Mensagem de 1892, o governador do estado afirmava que a corrente imigratória já se encontrava "encaminhada" e que conviria "fomentá-la fazendo-se propaganda nos centros populosos da Europa por meio de imprensa e folhetos" (Mensagem, 1892: 12). Na Mensagem de 1895, afirmava-se que o sucesso da colonização por imigrantes era fruto da expectativa de tornarem-se "proprietários de um pedaço de terra, por preço reduzido e longo prazo, e que gozarão, sem diferença dos nacionais, de plena liberdade civil e religiosa" (Mensagem, 1895: 23). 
Na Mensagem de 1901, o chefe do Executivo apresentou o seguinte balanço: 53.047 imigrantes teriam chegado ao Paraná entre 1889 e 1900. Segundo ele, não seria necessário retomar a "imigração subvencionada" interrompida pela União em 1896, porque o estado, tendo em vista seu clima, a qualidade de suas terras e a prosperidade das colônias existentes, não tinha necessidade desse tipo de apoio (Mensagem de 1901: 9). Não obstante o otimismo declarado, na Mensagem de 1902 o chefe do Executivo afirmava que o fluxo de imigrantes tinha decrescido nos anos anteriores, enquanto as Mensagens de 1903 e 1904 não faziam menção à questão da imigração, embora se saiba que neste último ano tivesse sido votada uma linha de crédito para subsidiar o transporte de imigrantes europeus. Finalmente a Mensagem de 1905 apresentava um balanço sombrio sobre a questão: desde que o governo federal rescindira os contratos para a "introdução de novos imigrantes", as "grandes levas de imigrantes desapareceram". Para retomar o fluxo de entradas fazia-se necessário pagar os custos da viagem da Europa ao Brasil (o que, a despeito da linha de crédito, não vinha sendo feito) ou, na pior das hipóteses, fazer "propaganda" (Mensagem de 1905: 38-40).

A Mensagem de 1906 trazia uma novidade. Aproveitando-se de uma linha de crédito para subsidiar o transporte de imigrantes, concedida já em 1904, ratificada em 1905, mas até então não utilizada, o Presidente do estado firmara contrato, pelo prazo de um ano, com as Companhias Loyd Austríaco e Real Húngara de Navegação Marítima ${ }^{18}$ (Mensagem de 1906: 43-44). Em 1907, o estado decidiu criar uma

Comissão de Colonização incumbida da verificação de lotes devolutos e condições de efetivo aproveitamento; de examinar as melhores terras públicas e privadas indicando a nacionalidade e aptidões dos colonos que as devem ocupar, devendo ainda o Chefe desta comissão previamente entender-se com os Poderes da União a fim de estabelecer bases para um serviço comum entre os Governos Federal e estadual. (Mensagem de 1907: 19)

Esse retorno da parceria com a União inscrevia-se no contexto de criação do novo "Ministério da Agricultura". Em consequência, em 1908, ao contrário do que havia sido feito em 1896, o estado procedeu à devolução de "terras públicas” à União, demarcou lotes em colônias já existentes, como Prudentópolis, e decidiu ainda criar uma "colônia-modelo" em uma área próxima a Curitiba, cujo objetivo específico seria demonstrar a viabilidade de determinadas culturas em “zonas temperadas" (Mensagem de 1908: 16-17). Em 1909, outra linha de crédito, dirigida desta feita à colônia de Afonso Pena (Mensagem de 1909: 8). Essas 
iniciativas - desde o contrato com as companhias marítimas, passando pelas agências burocráticas ligadas à imigração/colonização até a "devolução" das terras públicas à União - demonstram que, embora os imigrantes fossem bem-vindos e necessários para impulsionar o binômio colonização/produção agrícola sobre o qual a imigração havia sido assentada, a capacidade de intervenção do Paraná era limitada. Do mesmo modo, recolocando suas "terras públicas" à disposição da União, o poder local se alinhava definitivamente ao Decreto 6.455 (19 de abril de 1907), através do qual a União criava o Serviço de Povoamento do Solo Nacional, ${ }^{19}$ inscrevendo a imigração em sua política de ocupação e de desenvolvimento.

Segundo Ramos (2006: 91-98), o decreto era muito completo. As competências do Serviço foram divididas em 4 títulos e 138 artigos. Para além do controle da documentação, condições de saúde e eventual repatriamento, o objetivo principal era atrair imigrantes colonizadores com idade inferior a 60 anos que "se disponham a fixar-se como proprietários rurais" (Baily, 1931 apud Ramos, 2006: 94). A intenção de criar uma pequena classe de proprietários rurais (colonos) parecia ser tão evidente que só "em casos excepcionais" se subsidiaria a vinda de imigrantes que desejassem apenas trabalhar sem tornarem-se proprietários. ${ }^{20}$ Para redirecionar esses fluxos migratórios de europeus desejosos de se instalar nos núcleos coloniais existentes (ou em núcleos em vias de constituição), a União financiaria tanto as passagens internacionais e os deslocamentos do porto do Rio de Janeiro aos estados, quanto a aquisição dos lotes, cuja cobrança de dívidas e remissão de títulos de propriedade (provisórios ou definitivos) ficaria a cargo dos funcionários federais.

O decreto previu ainda formas de articulação entre as esferas federal e estadual tais como auxílio local na escolha e na transferência de terras para a União, ${ }^{21}$ recepção dos imigrantes, quando não desembarcassem no Rio de Janeiro, assentamento, definição de espaços reservados às escolas e igrejas no interior dos núcleos, entre outros. Previu finalmente que a venda de lotes aos "nacionais", nos núcleos coloniais fundados ou mantidos pela União, não poderia exceder $10 \%$ do total. Em relação ao Paraná, a ação do Serviço foi muito importante. Entre 1908 e 1914, de um total de 12.330 poloneses que se haviam estabelecido no estado, 9.880 residiam em colônias criadas ou mantidas pela União. O controle dessas colônias duraria mais do que o previsto. A título de exemplo, a colônia de Cruz Machado, onde viviam 5 mil poloneses, ficou sob o controle da União durante 14 anos e 5 meses a partir da data de sua criação, no dia 19 de dezembro de 1910. É de estranhar assim que as Mensagens (entre os anos 1910 e 1915) apresentem apenas raras e superficiais referências (aquisição e cessão de terras) aos esforços da União no processo de imigração/colonização do estado. Talvez, após a transferência do controle das colônias para a União, o interesse local por elas se 
tenha restringido ao acompanhamento da situação e ao registro de entradas de imigrantes no estado. Mas se as ações do Serviço tentaram disciplinar o fluxo de imigrantes, elas não explicam as razões da partida, nem mesmo a escolha do Brasil (e do Paraná) como porto de destino. Assim é que, para se entender as razões da forte emigração polonesa para o Paraná, necessário é ultrapassar tanto a dimensão local quanto a nacional, uma vez que o Serviço, apesar da propaganda realizada na Europa, só se ocupava do imigrante após sua chegada no território brasileiro.

\section{A emigração polonesa: história e representações}

Do outro lado do Atlântico, nos territórios poloneses ocupados pelo Império Russo (também chamados de Congresso Polonês), de onde partiu a maior parte dos poloneses que vieram para o Brasil, a situação dos camponeses, comparada ao período anterior, em nada havia progredido. A queda do preço dos cereais provocada pela abertura do mercado local à concorrência internacional (sobretudo dos EUA e do Canadá), provocando grande miséria naquelas áreas rurais, associada à rápida industrialização de cidades como Varsóvia e Lodz, era um dos mais importantes fatores de mobilidade, culminando tanto na emigração para regiões rurais ricas da Prússia, quanto na emigração em massa tanto para os EUA quanto para o Brasil. Some-se a isso o fato de que uma propaganda tão fantástica quanto eficaz sobre o Paraná se espalhou no seio do campesinato, provavelmente disseminada por agentes particulares ligados às companhias marítimas. A título de exemplo, afirmava-se que o governo brasileiro estaria disponibilizando gratuitamente aos imigrantes enormes quantidades de terra; que a "rainha do Brasil" - de fato a Imperatriz Teresa Cristina, esposa de Pedro II -, pouco antes de sua morte, havia oferecido suas terras aos camponeses; que o Papa ${ }^{22}$ havia entregado o Paraná aos poloneses, ou ainda que o Brasil era um país tão rico que não havia necessidade de trabalhar.

Os imigrantes que chegavam ao Brasil eram, em sua maioria (95\%), camponeses. O Império Russo, ao contrário da Prússia, não lhes permitia emigrar. Para partir, às vezes mesmo para alcançar os portos de Bremen e de Hamburgo na Prússia, eles necessitavam de dinheiro e de um passaporte que só obteriam das autoridades da Prússia, o que os obrigava a emigrar como alemães. Diante dessas dificuldades, após a chegada ao Brasil, dinheiro e documentos eram reenviados aos familiares, realimentando o fluxo migratório. ${ }^{23}$ Ao lado desses últimos, outro tipo de documento que atravessava o Atlântico eram as cartas. Alguns fatos incomuns envolvendo essa correspondência merecem nossa atenção. 
Embora nem todos os imigrantes soubessem ou estivessem habituados a escrever, o fato é que as cartas se tornaram o único meio de comunicação entre familiares ou amigos e, por isso, foram numerosas. Mas isso seria difícil de provar hoje se não fosse uma prática trabalhosa e, finalmente, pouco eficaz, utilizada pelo Império Russo. Em sua tentativa de impedir a partida em massa, as autoridades czaristas instituíram uma engenhosa prática de triagem, apreensão ou censura da correspondência trocada entre membros de famílias separadas pela emigração. Acreditaram que o rompimento da comunicação frearia o ímpeto emigratório. Em consequência, milhares de cartas enviadas de diferentes países acabaram nas Atas das chancelarias czaristas, sendo recuperadas posteriormente e guardadas no Arquivo Público polonês. Infelizmente, somente uma pequena amostra dessas cartas, 250, foi salva do fogo que se alastrou por Varsóvia quando da insurreição de $1944 .{ }^{24}$ Do lote salvo, 60 cartas, chegadas na Polônia entre 1890 e 1891, foram enviadas do Brasil, em particular do Paraná. ${ }^{25}$

Tendo analisado o conteúdo dessas cartas, Kula (1977) nos informa que o tom geral é de otimismo. Segundo esse autor, o objeto da censura eram as cartas que traziam boas novas, enquanto aquelas que traziam más notícias, ou relatos sobre as dificuldades que enfrentavam os emigrantes, eram entregues aos seus destinatários. ${ }^{26}$ Os relatos de Hempel (1973) confirmam essa tese, porque os testemunhos que ele pôde recolher quando de sua estada no Brasil atestam um grande número de dificuldades - desde os maus tratos quando da chegada à ilha das Flores ${ }^{27}$ até as doenças, sobretudo o cólera, e o falecimento das crianças, em virtude das péssimas condições de higiene - suportadas nas moradias de baixa qualidade no Paraná e em Santa Catarina onde estiveram inicialmente à espera da demarcação dos lotes.

As cartas "otimistas", normalmente endereçadas aos membros das famílias, frequentemente começavam pela evocação religiosa associada ao estado de saúde do remetente: "Estou com saúde graças a Deus todo Poderoso". Numa ou noutra carta, lê-se a descrição dos cultos, a referência aos padres e às igrejas em madeira. As cartas frequentemente terminavam indicando o endereço do remetente, de fato o nome da colônia onde se encontrava. Em relação aos temas principais, as cartas descreviam as casas e as terras, desde sua fertilidade, passando pela riqueza e diversidade dos bosques (de onde os imigrantes retiravam livremente a madeira necessária à construção de suas casas), até a beleza das paisagens, da vegetação e da fauna, sobretudo os passarinhos. O clima, sobretudo a suavidade do inverno, tinha lugar de destaque. Há muitas passagens sobre o tamanho das propriedades que lhes eram demarcadas, sendo afirmado que não havia a necessidade imediata de contrapartida em termos de trabalho ou dinheiro. A vida social não era esquecida. A ordem pública vinha em primeiro lugar. Em seguida, a harmonia das relações sociais (inclusive com os ex-escravos), a liberda- 
de, a ausência de "senhores", o respeito com o qual as elites os tratavam e o fato de não necessitarem pagar impostos. Originários de regiões recém-egressas da servidão, as relações sociais "igualitárias", fato surpreendente num país marcado pela escravidão, foram especialmente notadas. Em resumo, o tom era realmente positivo e a situação geral era descrita como boa, por vezes melhor mesmo do que nos territórios ocupados, confirmando a tese da censura das "cartas otimistas".

Além das cartas, esse período nos forneceu ainda testemunhos - sob a forma de memórias (Saporski, 1972; Koscianski, 1971) - e análises - sob a forma de relatos de viagens ao Paraná - realizados no contexto dos debates que, nos territórios poloneses ocupados, opuseram partidários e não-partidários da emigração. Entre estes últimos sobressaíam-se os de Hempel (1973) e Klobukowski (1971), membros da mesma expedição científica enviada ao Brasil e à Argentina no começo dos anos 1890 a fim de conhecer em detalhes as condições de vida e de trabalho dos emigrantes poloneses. Os dois relatos concordam que, diferentemente dos Estados Unidos, o Brasil, particularmente seus estados meridionais, não deveria ser visto simplesmente como um país de destino. Hempel tornou-se partidário da emigração porque viu aí as melhores condições de "sobrevivência da vida polonesa", então ameaçada (Hempel, 1973: 16). Klobukowski, um intelectual que se havia interessado pelo problema da emigração, foi mais longe. Tendo em vista as condições e o número de poloneses residentes no Paraná, afirmou que estavam reunidas ali condições para o nascimento de uma "sociedade neopolonesa" (Klobukowski, 1971: 15).

De fato, desde a segunda metade do século XIX, nacionalistas poloneses começaram a avaliar positivamente o potencial colonizador dos emigrantes. "Assim como seus homólogos [italianos e alemães], eles baseavam suas esperanças na formação de colônias agrícolas homogêneas, sobretudo no Paraná brasileiro, onde, segundo Josef Siemiradzki, emergia uma nova Polônia" (Gabaccia et al., 2006: 86-87). De fato, a ideia de fundar uma colônia em território brasileiro, assim como outras potências europeias haviam feito no continente africano, lhes pareceu uma possibilidade real. Cichoka (2002) se referiu a essa questão nos seguintes termos:

É curioso notar a mudança progressiva das mentalidades e ver como, a partir do século XIX, começa a se concretizar a ideia patriótica de fazer ressuscitar a Polônia no Brasil ou na Argentina. Os partidários dessa ideia, vivendo em grande parte nos antigos territórios poloneses, preconizavam a criação de muitos estados poloneses no Brasil unidos sob o nome de "Nowa Poslka", Nova Polônia, e se organizavam para fazer vir para estes estados todos os imigrantes poloneses, sobretudo aqueles residentes nos EUA. 
É possível pensar ainda que a ideia de fundar uma "Nowa Polska" no Brasil tivesse relação com o quadro de vida dos poloneses no Paraná. Isso porque, na época, no seio das colônias, os imigrantes começaram a fundar suas primeiras formas de organização social, particularmente as escolas bilíngues, os órgãos de imprensa e as associações civis. Entre as últimas, é de se notar a Sociedade Polono-Brasileira Tadeuz Kosciusko, ${ }^{28}$ fundada em 1890 a partir da constatação de que os imigrantes haviam-se isolado demais do "mundo civilizado". A Sociedade de Ginástica Falcão (1898), o Círculo da Mocidade Polonesa (1901), a Sociedade Santo Estanislau (1906), a Sociedade União Polonesa (1920), a Sociedade de Educação Física Junak (1923) e a Associação de Estudantes Sarmatia (1926) foram outras formas de organização criadas. Note-se ainda que, entre 1892 e 1914, 19 jornais foram fundados em Curitiba. Alguns tiveram vida curta, mas outros apareceram regularmente, como foi o caso do jornal Gazeta Polska w Brazylii, editado entre 1892 e 1941. A intensidade da vida social parece ter sido de tal monta que mesmo a imprensa estabelecida nos antigos territórios, quase que totalmente contrária à emigração, também enviou "seus" correspondentes ao Brasil e à Argentina. A despeito das reportagens desfavoráveis, ${ }^{29}$ o fluxo migratório não foi interrompido e a ideia de que a emigração poderia defender os interesses do "país" no estrangeiro acabou por se impor também nesse campo. Em resumo, as associações, as escolas e os órgãos de imprensa aparentemente modificaram a vida social dos imigrantes. Aproximando imigrantes que não necessariamente se conheciam, contribuíram para construir, em torno de uma nova identidade polonesa, sociabilidades rompidas com a emigração. Mas isso num novo estilo de vida mais livre, embora não isento de conflitos. ${ }^{30}$

Consequentemente, para grupos de poloneses não emigrados, seus conterrâneos instalados em outros países não deveriam ser tratados como colonos cujo destino era povoar e/ou se fazer assimilar por outras culturas. Isso parece explicar por que, logo após a reconquista de sua independência, o Estado polonês decidiu estabelecer em Curitiba, uma cidade pouco importante na época, um consulado, nomeando para o posto Kazimierz Gluchowski (1885-1941). ${ }^{31}$ Esse primeiro cônsul era nacionalista e defensor da posição "colonizadora" e, quando chegou à cidade, em 1920, foi recebido em festa. Mas é possível fazer o raciocínio inverso, ou seja, supor que foram as colônias de imigrantes que suscitaram nos nacionalistas poloneses a possibilidade de realizar projetos neocolonialistas. Sob um ou outro ponto de vista, o fato é que a ideia de uma imigração orquestrada apenas pelo país de destino ou ainda a clássica dicotomia entre imigração espontânea e imigração oficial, por si sós, são incapazes de compreender as redes que se formam a partir dos fluxos migratórios.

Nas décadas de 1920 e 1930 (até a "campanha de nacionalização" organizada pelo governo Vargas), o governo brasileiro continuou a ver os imigrantes como atores de um projeto de povoamento. Mas nem os imigrantes nem mesmo 
os dirigentes políticos da "jovem" nação polonesa parecem ter sido informados disso. Ao contrário, "por mais irrealista que tenha sido, o sonho de colônias polonesas na América do Sul persistiu até os anos 1930" (Gabaccia, 2006: 89).

\section{Conclusão}

O caso da imigração polonesa serve para demonstrar a distância que separa o imigrante do emigrante. Permite ainda observar a complexidade dos processos migratórios e a representação que deles fazem os diversos atores. Os estudos brasileiros focaram preferencialmente um dos aspectos das migrações internacionais, particularmente aquele que trata da vida dos imigrantes e dos processos de assimilação, de aculturação ou ainda de resistência cultural no país de destino. Outros aspectos da questão aguardam novas pesquisas.

Notas

1. Neste mesmo registro, Devoto (2004:51-59) fala em "otimistas", quando as condições no país de chegada pareciam "atrair" os imigrantes, e "pessimistas", quando eram as condições nos países de origem que pareciam "expulsar" os emigrantes.

2. Ainda que o Estado polonês não existisse à época da imigração, chamamos aqui de poloneses todos aqueles imigrantes que assim se declararam em sua chegada ao Brasil.

3. Gluchowicz (2005:45) afirma que 104 mil poloneses entraram no Brasil. Mas tendo em vista a ocupação da Polônia, Wachowicz (1999:16) estima em 25\% o número de imigrantes alemães que talvez fossem poloneses. Essa estimativa elevaria para 130 mil o número de imigrantes poloneses.

4. Todos os anuários demográficos brasileiros estão disponíveis em http://www.ibge.gov.br
5. Existem dois tipos de relatórios que foram enviados entre 1854 e 1889 seja à Assembleia Provincial, seja ainda ao futuro presidente da província, um pelo presidente e outro pelo vice-presidente. Em alguns anos, encontramos dois relatórios. No primeiro caso, foram enviados por diferentes presidentes, no caso de a província ter conhecido mais de um presidente para aquele ano específico. No segundo, foram enviados pelo mesmo presidente. Citamos sempre Relatório, ano, seguido do número 1 ou 2 entre parênteses, e página, como a seguir: Relatório, 1873 (1): 43. Esses relatórios estão disponíveis em www.crl.edu/ content/brazil/parn.htm.

6. Edmundo Sebastião Wós Saporski nasceu em Opole (Silésia) em 1844 e morreu em Curitiba em 1933. Em 1870, Saporski visitou Curitiba pela primeira vez e constatou que nenhum polonês residia ali. É considerado o "pai da 


\section{Origens do Brasil meridional}

imigração polonesa” para o Paraná. Para maiores detalhes, ver seu depoimento em Saporski (1972).

7. O apoio veio do então presidente da província, Venâncio José de Oliveira Lisboa, que, pouco antes, havia criado a primeira colônia de imigrantes após a emancipação, Colônia Dr. Venâncio, situada a $12 \mathrm{~km}$ de Curitiba, com 116 alemães e 27 suecos.

8. Os documentos consultados estão publicados nos Anais da Comunidade Brasileiro Polonesa (1971 e 1973). Contudo, eles apresentam difícil solução. Por exemplo, a ortografia dos nomes ou mesmo o número de imigrantes não se repetem de um documento a outro, o que torna a pesquisa especialmente trabalhosa.

9. Neste mesmo Relatório, Lins refere-se aos poloneses como colonos "laboriosos e morigerados", imagem que lhes seria novamente associada nas décadas seguintes.

10. Duas colônias e 12 núcleos coloniais se localizavam no litoral. No $2^{\circ}$ Distrito (Curitiba e regiões vizinhas), existiam 18 colônias, entre as quais 5 "emancipadas". No município da Lapa, 3 núcleos, no município de Palmeira, 7 núcleos, e no município de Ponta Grossa, 17 núcleos, além da Colônia Assunguy.

11. Pode-se imaginar que, entre estes, muitos partiram ou então adquiriram a nacionalidade brasileira porque os dados oficiais (Censo de 1890) apresentam apenas 5.135 estrangeiros (poloneses e outros) residindo no Paraná.

12. O fluxo teria sido tão importante que nos territórios poloneses ocupados a partida em direção ao Brasil ficaria conhecida pela expressão "ele pegou a febre". Ver Mazurek (2008).

13. Assinale-se aqui a criação de algumas colônias ditas "mistas", ou seja, ocupadas por poloneses e ucranianos, por exemplo. É o caso da Colônia de Prudentópolis, a maior do estado, fundado por 2.500 poloneses e 7.500 ucranianos.

14. Contudo, apenas em 1893 (Decreto 144 de 5/7/1893) o governo autorizou de fato o pagamento prometido.

15. As "terras devolutas" pertenciam à União do ponto de vista puramente geográfico, uma vez que estavam localizadas no interior do país e não estavam ocupadas. Assim, podiam servir aos objetivos da colonização.

16. Havia, contudo, uma exceção feita aos "nativos da Ásia e da África que só poderiam entrar no país com uma autorização do Congresso Nacional". Decreto 258, 28 de junho de 1890 (Ministério da Agricultura, Indústria e Comércio. Legislação Agrícola Brasileira. Rio de Janeiro: Imprensa Nacional, 1931 apud Ramos, 2006).

17. Todas essas "mensagens" estão disponíveis em www.crl.edu/content/ brazil/parn.htm. Seguindo o padrão já descrito, apresentamos as mensagens, seguidas do ano e da página, quando for o caso, conforme o modelo "Mensagem 1892: 12”.

18. Esses contratos previam o transporte de imigrantes em $3^{\mathrm{a}}$ classe dos portos europeus de Trieste, Gênova e Fiume (todos na Itália) até o porto de Paranaguá.

19. Essa agência seria subordinada ao Ministério da Viação e Obras Públicas. Na sua estrutura, constava um diretor geral e inspetores para cada estado do país. Doravante, abreviamos para 'Serviço'.

20. Rompia-se assim com a vinculação entre imigração e trabalhadores agrícolas para as fazendas de café de São Paulo e resgatava-se a associação positiva entre imigração, ocupação e produção agrícola.

21. Segundo Ramos (2006: 135-137), o processo de transferência de terras públicas dos estados para a União não foi tranquilo. Em certos casos, as terras colocadas à disposição da União estavam 
ocupadas, o que teria provocado conflitos entre os nacionais e os agentes do Serviço.

22. Holanda, no prefácio do livro Memórias de um colono no Brasil, p. XIX, apresenta um relato completo dessa “doação".

23. Alguns remetentes informam em suas cartas as dificuldades de enviar dinheiro do Brasil para os territórios sob dominação russa. Os valores eram confiscados (ou simplesmente roubados), o que provocou inúmeras reclamações dos imigrantes junto às autoridades brasileiras. Obrigado a reembolsar os valores não entregues, o correio brasileiro acabou por cancelar o envio de valores à Rússia. Para maiores detalhes, ver Kula (1977).

24. Trata-se da primeira e fracassada tentativa feita por poloneses residentes em Varsóvia de expulsar o exército alemão que então ocupava a cidade. Há hoje em Varsóvia um museu dedicado a essa insurreição, o Muzeum Powstania Warszwskeigo. Pode ser visitado no sítio www.1944.pl.

25. A primeira carta traz o número $22 \mathrm{e}$ está datada de 15 de novembro de 1890 , e a última traz o número 82 , de 24 de maio de 1891. Elas foram traduzidas e publicadas nos Anais da Comunidade Brasileiro Polonesa, vol. 8, 1977, p. 21-117.

26. Ao final de muitas das cartas confiscadas, o censor escrevia a palavra

\section{Referências bibliográficas}

zadierzat, seguida de um pequeno resumo do conteúdo encontrado. Numa outra carta, a de $n^{\circ} 40$, o remetente avisa ao destinatário que se o "moscovita" permitir ele escreverá novamente.

27. Trata-de da Hospedaria de Imigrantes Ilha das Flores, fundada pela Inspetoria de Terras e Colonização em 1883. Funcionou até 1966.

28. A Sociedade fundou uma escola primária, um coral e uma pequena banda de música. Sua ação foi especialmente importante na organização do Primeiro Congresso Polonês, cujo objetivo era reunir todos os poloneses residindo na América do Sul com vistas a atuar para a reconquista da independência da Polônia.

29. Entre os não partidários da emigração encontram-se o padre Z. Chelmicki e M. Glinka, ambos membros da Sociedade Agrícola de Varsóvia. Ambos visitaram o Brasil em 1891 e publicaram, em Varsóvia, diversos artigos contra a emigração.

30. Segundo Wachowkski (198:109-110), houve inúmeros conflitos entre professores e padres.

31. Gluchowski ocupou o cargo de cônsul até em 1922, quando começou a redigir o livro Os poloneses no Brasil (Gluchowski, 2005). Seu plano de fundar uma colônia polonesa no Paraná foi concebido quando de seu retorno à Polônia, em 1928.

ANDREAZZA, Maria. L. 1996.

Paraíso das delícias: estudo de um grupo de imigrantes ucranianos. Tese (Doutorado) - UFPR, Curitiba. 


\section{Origens do Brasil meridional}

BLANC-CHALEARD, Marie-Claude. 2001. Histoire de l'immigration. Paris:

La Découverte (Collection Repères).

CICHOKA, Marta. 2002. Les polonais en Amérique Latine: un autre regard. Amérique Latine Histoire e Mémoire, n. 4. Disponível em: $<$ htpp://alhim.revues. org/document 483.html > . Acesso em: 12 de junho de 2008.

DEVOTO, Fernando 2004. Historia de la inmigración en Argentina. Buenos Aires: Editorial Sudamericana.

GABACCIA, Donna. R et al. 2006. Émigration et construction nationale en Europe. In : GREEN, Nancy \& WEIL, François. Citoyenneté et émigration. Les politiques du départ. Paris: EHESS. p. 67-94.

GLUCHOWSKI, Kasimierz. 2005. Os poloneses no Brasil. Porto Alegre: Rodzicz \& Ordakowski.

GREEN, Nancy. 1994. L'odyssée des émigrants. Et ils peuplèrent l'Amérique. Paris: Gallimard (Colletion La Découverte).

GRITTI, Isabel R. 2004. Imigração e colonização polonesa no Rio Grande do Sul. A emergência do preconceito. Porto Alegre: Martins Livreiro.

GUÉRIOS, Paulo. R. 2006. Memória, identidade e religião entre imigrantes rutenos e seus descendentes no Paraná. Tese (Doutorado) - Museu Nacional-UFRJ, Rio de Janeiro.

HANDA, Tomoo. 1987. O imigrante japonês. História de sua vida no Brasil. São Paulo: T. A. Queiroz/Centro de Estudos Nipo-Brasileiros.

HEMPEL, Antonio. 1973. Os poloneses no Brasil. Anais da Comunidade Brasileiro-Polonesa. Curitiba: Superintendência do Centenário da Imigração Polonesa ao Paraná, vol. 7, p. 11-99.

HOLANDA, Sérgio B. 1980. Prefácio. In: DAVATZ, T. Memórias de um colono no
Brasil (1850). Belo Horizonte: Itatiaia; São Paulo: Edusp.

KERSTEN, Márcia S. de A. 1983.O colono-polaco: a recriação do camponês sob o capital. Dissertação (Mestrado em História) - SCHLA-UFPR, Curitiba.

KLOBUKOWSKI, Estanislau. 1971. Recordações de viagem. Anais $d a$ Comunidade Brasileiro-Polonesa. Curitiba: Superintendência do Centenário da Imigração Polonesa ao Paraná, vol. 4, p. 15-107.

KULA, Marcin. 1977. Carta dos imigrantes do Brasil. Anais da Comunidade Brasileiro-Polonesa. Curitiba: Superintendência do Centenário da Imigração Polonesa ao Paraná, vol. 8, p. 9-117.

MAZUREK, Jerzy. 2008. Entrevista concedida ao autor. Varsóvia, 20 de março de 2008.

OLIVEIRA, Márcio de. 2007. Imigração e diferença em um estado do Sul do Brasil: o caso do Paraná. Nuevo Mundo - Mundos Nuevos, v. 7. Disponível em: http://www.nuevomundo.revues.org. Acesso em: 25 de maio de 2008.

RAMOS, Jair de S. 2004. La construction de l'"immigrant indésirable" et la nationalisation de la politique d'immigration brésilienne. In: RYGIEL, $\mathrm{P}$. (sous la dir.). Le bon grain et l'ivraie. Paris: Aux Lieux d'Être. p. 75-97.

. 2006. O poder de domar do fraco: construção de autoridade e poder tutelar na política de povoamento do solo nacional. Niterói: Eduff.

ROCHE, Jean. 1959. La colonisation alemande et le Rio Grande do Sul. Paris: IHEAL.

SAKURAI, Célia. 2000. Imigração japonesa para o Brasil. In: FAUSTO, B. (org.). Fazer a América. $2^{\mathrm{a}}$ ed. São Paulo: Edusp. p. 215-229. 
SAPORSKI, Sebastião W. 1972.

Memórias. Anais da Comunidade

Brasileiro-Polonesa. Curitiba:

Superintendência do Centenário da

Imigração Polonesa ao Paraná, vol. 6, p. $11-100$.

SEYFERTH, Giralda. 1974. A colonização alemã no Vale do Itajaí-Mirim. Porto Alegre: Movimento.

. 1997. A assimilação dos imigrantes como questão nacional. Mana, Rio de Janeiro, vol. 3, n. 1, p. 95-131.

.1999. Os imigrantes e a campanha de nacionalização do Estado Novo. In: PANDOLFI, D. (org.). Repensando o Estado Novo. Rio de Janeiro: FGV. p. 199-228.

. 2000. A colonização alemã no Brasil: etnicidade e conflito. In: FAUSTO, B. (org.). Fazer a América. $2^{\mathrm{a}}$ ed. São Paulo: Edusp. p. 273-313.

THOMAS, Williams I. \& ZNANIECKI, Florian. 1996. The Polish peasant in Europe and America. A classic work in immigration history. Edited by Eli Zaretsky. Chicago: University of Illinois Press.

TORPEY, John. Du sévage au "libre départ". In: GREEN, Nancy \& WEIL, François. Citoyenneté et émigration. Les politiques du départ. Paris: EHESS. p. 19-36.
WACHOWSKI, Romão. 1971. Memórias de Koscianski. Anais da Comunidade Brasileiro-Polonesa. Curitiba: Superintendência do Centenário da Imigração Polonesa ao Paraná, vol. 3, p. 36-79.

WACHOWICZ, Rui C. 1981. O camponês polonês no Brasil. Curitiba: Fundação Cultural de Curitiba/Casa Romário Martins.

. 1999. Aspectos da imigração polonesa ao Brasil. Projeções. Revista de Estudos Polono-Brasileiros, Curitiba, ano 1 , vol. 1, 10-31.

WENCZNOWICZ, Thaís J. 1977. Tomás Coelho: uma comunidade camponesa. Curitiba: Real Artes Gráficas.

2009. Imigração polonesa no Rio Grande do Sul. In: MAZUREK, J. Os poloneses sob o Cruzeiro do Sul. Varsóvia: Instituto de Estudos

Ibero-Americanos. p. 107-143.

WILLEMS, Emilio. 1946. $A$ aculturação dos alemães no Brasil. São Paulo: Companhia Editora Nacional.

ZOLBER, Aristide R. 2006. La Révolution des départs. In GREEN, Nancy \& WEIL, François. Citoyenneté et émigration. Les politiques du départ. Paris: EHESS. p. 37-66.

\section{Resumo}

$\mathrm{O}$ artigo discute as origens do "Brasil meridional" a partir do caso da imigração polonesa para o estado do Paraná (Brasil), ocorrida entre 1870 e 1920. Inicialmente, apresenta-se uma discussão sobre modelos explicativos das causas da imigração para o Brasil. Em seguida é apresentada, em linhas gerais, a história da imigração polonesa. Neste histórico, é trabalhado o contexto sociopolítico nas regiões de que partiram os imigrantes, o impacto das políticas federais e estaduais sobre a imigração e a função que os imigrantes deveriam desempenhar no desenvolvimento do estado do Paraná. Após 1890, analisa-se ainda a forma como os emigrantes foram descritos nos 
territórios poloneses ocupados e o papel que foram chamados a desempenhar no processo de reconquista da independência da Polônia. Uma breve discussão sobre a distância que separa o imigrante do emigrante no interior da história social brasileira fecha este trabalho.

Palavras-chave: Paraná, Brasil meridional, imigração, emigração, poloneses, Polônia

\section{Abstract}

This paper discusses the origins of Southern Brazil focusing on the case study of Polish immigration in the state of Paraná, between 1870-1920.

Initially, we present an overview of immigration scientific models in Brazilian social sciences. Next, we summarize the history of Polish immigration in Paraná. We discuss the social and political context at the departure areas, the impact of federal and local policies (push factors) over immigrants and their role in the development of the state. After that, we show how they are considered in ancient Polish European areas and the role they were claimed to play in the process of independence recovering of the Polish State. Finally, we present a short discussion about the distance between immigrants and emigrants in Brazilian social history.

Key words: Paraná, southern Brazil, immigration, emigration, Polish, Polland

\section{Résumé}

Cet article a pour objet l'étude des origines du Brésil méridional à partir du cas de l'immigration polonaise dans l'état du Paraná entre 1870 et 1920 . Au début, on présente une discussion sur les modèles explicatifs des causes de l'immigration au Brésil. Ensuite, on présente les grands traits historiques de l'immigration polonaise. On analyse notamment le contexte socio-politique dans les régions d'où sont partis les immigrants, l'impact des politiques fédérales et locales d'attraction et la fonction qu'ils devraient remplir dans le processus d'occupation et de développement de l'état. Après 1890, on analyse la façon dont les émigrants ont été décrits dans les anciens territoires polonais occupés et le rôle qu'ils devraient jouer dans le processus de la reconquête de l'indépendance de la Pologne. Lanalyse sur la distance qui sépare l'émigrant de l'immigrant à l'intérieur de l'histoire social brésilienne clôt ce travail.

Mots clés: Paraná, Brésil méridional, immigration, émigration, polonais, Pologne 